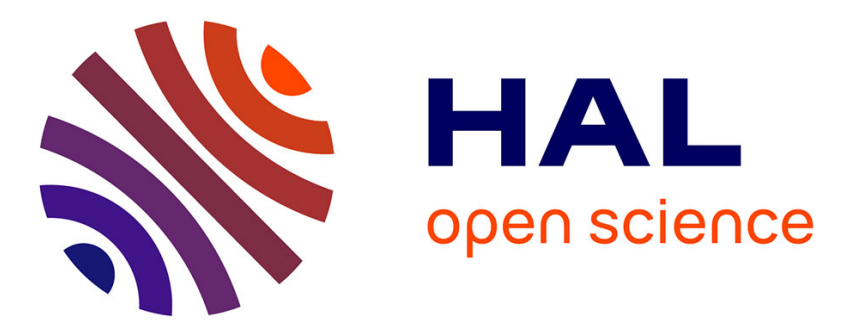

\title{
Operation of prototype niobium gravitational radiation antenna with microwave parametric accelerometer
}

D.G. Blair, M.J. Buckingham, C. Edwards, J. Ferreirinho, D. Howe, R. James, F. van Kann, A.G. Mann

\section{- To cite this version:}

D.G. Blair, M.J. Buckingham, C. Edwards, J. Ferreirinho, D. Howe, et al.. Operation of prototype niobium gravitational radiation antenna with microwave parametric accelerometer. Journal de Physique Lettres, 1979, 40 (5), pp.113-115. 10.1051/jphyslet:01979004005011300 . jpa-00231580

\section{HAL Id: jpa-00231580 https://hal.science/jpa-00231580}

Submitted on 1 Jan 1979

HAL is a multi-disciplinary open access archive for the deposit and dissemination of scientific research documents, whether they are published or not. The documents may come from teaching and research institutions in France or abroad, or from public or private research centers.
L'archive ouverte pluridisciplinaire HAL, est destinée au dépôt et à la diffusion de documents scientifiques de niveau recherche, publiés ou non, émanant des établissements d'enseignement et de recherche français ou étrangers, des laboratoires publics ou privés. 


\title{
Operation of prototype niobium gravitational radiation antenna with microwave parametric accelerometer $(*)$
}

\author{
D. G. Blair, M. J. Buckingham, C. Edwards, J. Ferreirinho, \\ D. Howe, R. James, F. van Kann and A. G. Mann
}

Physics Dept., University of Western Australia, 6009

(Reçu le 23 août 1978, accepté le 17 janvier 1979)

\begin{abstract}
Résumé. - Nous rendons compte de résultats expérimentaux qui confirment la possibilité d'utiliser un accéléromètre micro-onde associé à une antenne de radiation gravitationnelle en niobium à haut facteur de qualité, le tout soulevé par lévitation magnétique sans le moindre contact. On décrit le fonctionnement d'une antenne prototype.
\end{abstract}

Abstract. - We report experimental results which confirm the feasibility of using a magnetically levitated noncontacting microwave accelerometer in conjunction with a high $Q$ levitated niobium gravitational radiation antenna. Operation of a prototype antenna is described.

1. Introduction. - As we have discussed elsewhere $[1,2]$ one approach to optimization of a GR antenna is to use $\mathrm{Nb}$ as an antenna material, exploiting its high acoustic $Q$, density, sound velocity, and its intrinsic superconducting properties. Magnetic levitation can provide near optimum vibration isolation and low loss suspension : antenna design therefore requires the bar diameter to be limited to that determined by the flux penetration field (Annealing : 10 hours at $1900^{\circ} \mathrm{C}, 10^{-9}$ torr). We have measured this in annealed and unannealed discs. Annealed samples, as expected, are inferior to unanealed samples, as shown in table I. Annealed bars however, can be levitated for diameters up to $0.21 \mathrm{~m}$ allowing levitation of a $3 \mathrm{~m} \times 0.21 \mathrm{~m}$ bar of mass $890 \mathrm{~kg}$.

Table I.

$\begin{array}{lcc} & \begin{array}{c}\text { Flux } \\ \text { penetration field }\end{array} & \begin{array}{c}\text { Maximum } \\ \text { bar diameter }\end{array} \\ & -\bar{T} & - \\ \text { Annealed } & 0.19 \mathrm{~T} & 0.21 \mathrm{~m} \\ \text { Unannealed } & 0.25 \mathrm{~T} & 0.37 \mathrm{~m}\end{array}$

Our $Q$-measurements show that annealing is essential to the attainment of high $Q$-values in $\mathrm{Nb}$. We have observed a $Q$ of $6 \times 10^{7}$ in a levitated annealed bar at $4.2 \mathrm{~K}, 10^{-2}$ torr, compared with $1.8 \times 10^{6}$ for a

(*) This paper was presented at the LT 15 Conference as a postdeadline paper. similar but unannealed bar under the same conditions. The former value is limited by eddy current losses in the $\mathrm{Al}$ cradle between the levitation coils and the bar, caused by modulation of the levitation field by the bar vibration. This magnetic damping can be characterized by a magnetic $Q$-value, [3]

$$
Q_{\mathrm{m}}=K M \omega_{0}^{5 / 2} / B^{2} A
$$

where $K$ is a geometric factor, $B$ is the levitation field, $A$ is the area of exposed normal metal, $M$ is the bar mass and $\omega_{0}$ its frequency. When this magnetic loss is removed by a NbTi shield to be described elsewhere [4] the $Q$-value should be raised to its intrinsic value which we estimate as $1.1 \times 10^{8}$.

The attainment of magnetic levitation and high $Q$ makes a massive $\mathrm{Nb}$ antenna appear attractive, as long as it can be operated without degradation by the associated readout device. A prototype system which achieves this is now described.

2. Prototype antenna. - The prototype GR antenna is illustrated in figure 1 . A $0.3 \mathrm{~m} \times 50 \mathrm{~mm} \mathrm{Nb}$ bar, is levitated on the field of two elongated pancake coils. The accelerometer has the form of a cylinder $8 \mathrm{~cm}$ diameter and $12 \mathrm{~cm}$ long, covered in NbTi sheet, and levitated on another pair of elongated pancake coils. Pancake coils A and B provide chassis-bar and baraccelerometer repulsion and drive coil $\mathrm{C}$ provides forces independent of displacement to compress the magnetic springs due to coils A and B. 


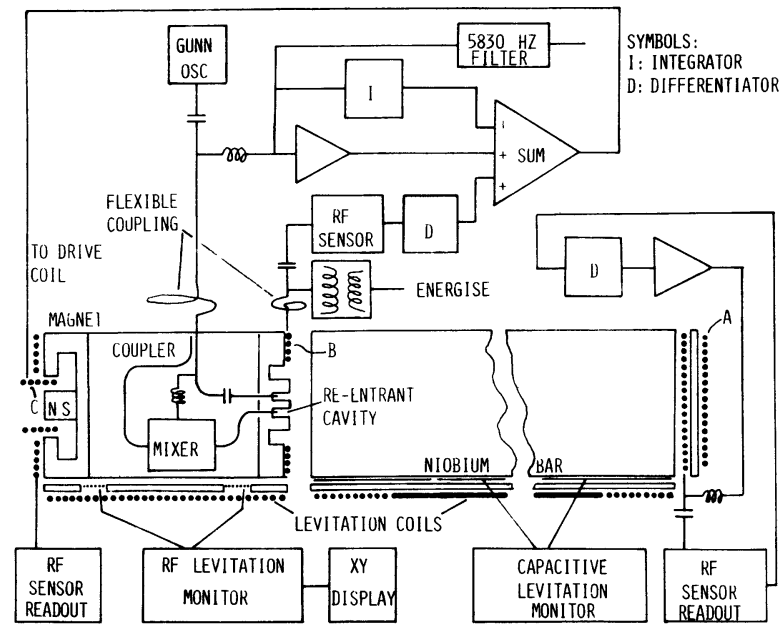

Fig. 1. - Schematic diagram of prototype antenna.

The re-entrant cavity is mounted at the front of the accelerometer. A $10 \mathrm{GHz}$ signal is coupled to the re-entrant cavity via a stripline directional coupler. The signal from the output of the cavity is mixed with the coupled incoming signal in a cryogenic mixer, giving voltage porportional to the phase shift across resonance. Resonance occurs when the spacing $x$ from the cavity centre pole to the antenna is $\sim 10^{-5} \mathrm{~m}$. The cavity $Q$ can be varied from $10^{2}$ to $10^{6}$ by varying the coupling of the input lines, thus varying the position bandwidth $\delta=x / Q$, of the cavity from $10^{-7} \mathrm{~m}$ to $10^{-11} \mathrm{~m}$. It is the small characteristic dimension, $x$, and even smaller position bandwidth $\delta$ (determined by the cavity $Q$ ) which leads to the high sensitivity of this transducer as a motion detector.

The accelerometer must be suspended parallel to the antenna to a precision of $\sim 0.1^{\circ}$ arc. To achieve this a levitation monitoring system has been constructed [5] which uses inductance modulated radiofrequency $L C$ resonators mounted between the levitation coils and the accelerometer. The $10^{-4} \mathrm{~mm}$ sensitivity of four separate sensors enables fine adjustments of position to be made by altering the currents in the levitation coils.

Adjustment of longitudinal position must bring the device into its $10^{-11} \mathrm{~m}$ working range. This is achieved by servo control using electronic damping of both the bar-accelerometer system, and the bar itself relative to the chassis. When levitated, the bar has a longi- tudinal sloshing mode $\sim 0.2-1 \mathrm{~Hz}$, depending on the strength of the magnetic springs. This is damped by the bar servo shown in figure 1, consisting of an RF inductive position sensor (mounted over coil A), differentiator and feedback. Bar-accelerometer relative motion is similarly damped by means of the RF inductive sensor $\mathrm{B}$ between the bar and accelerometer. This coil also supplies the necessary repulsion to obtain an equilibrium configuration between the levitated masses. Feedback is achieved by means of drive coil $\mathrm{C}$. When the relative motion of the baraccelerometer system is sufficiently reduced by the damping, the accelerometer can be manually tuned until an intermittent microwave pulse is observed as the accelerometer moves across resonance. Once this motion has been confined to within $3 \delta$ it is possible to lock the cavity onto resonance by introducing feedback of the mixer signal and its integrated value.

3. Operational results. - Apart from levitation the antenna has inadequate isolation from ground noise or boiling helium. Ambient vibration levels are $\sim 10^{-8} \mathrm{~m}$ in the $1-10 \mathrm{~Hz}$ range. Attainment of servo control in this environment requires the tightening of magnetic spring $B$ by using currents high enough in coils $\mathrm{A}, \mathrm{B}$ and $\mathrm{C}$ to bring the bar-accelerometer resonant frequency $f_{\mathrm{ba}}$ to $5-10 \mathrm{~Hz}$. Higher values of $f_{\text {ba }}$ cannot be achieved due to the small surface area at the end of the bar available for the application of magnetic fields. A larger diameter bar would allow greatly increased forces, enabling operation at 50$100 \mathrm{~Hz}$. However at $10 \mathrm{~Hz}$ the vibration isolation is sufficient to enable servo control for cavity $Q$ values up to at least $10^{3}$, the highest value so far tested.

Typical system waveforms are shown in figure 2 . In $(a)$ the $1 \mathrm{~Hz}$ sloshing motion of the bar was damped by the bar servo at the arrowed point. In $(b)$ the mixer signal shows spikes as the undamped accelerometer oscillates across resonance with amplitude $\sim 10^{-7} \mathrm{~m}$. In $(c)$ partial damping has reduced the motion to about $10^{-8} \mathrm{~m}$. In $(d)$ full servo control has reduced bar-accelerometer motion to $<4 \times 10^{-10} \mathrm{~m}$. A ring down curve for an unannealed $\mathrm{Nb}$ bar measured in helium at 50 torr is shown in $(e)$.

The present level of sensitivity of this system is still below that achievable by conventional techniques. The minimum detectable amplitude at $5.8 \mathrm{kHz}$ is $3 \times 10^{-16} \mathrm{~m}$, with a $3 \mathrm{~s}$ integration time. Several
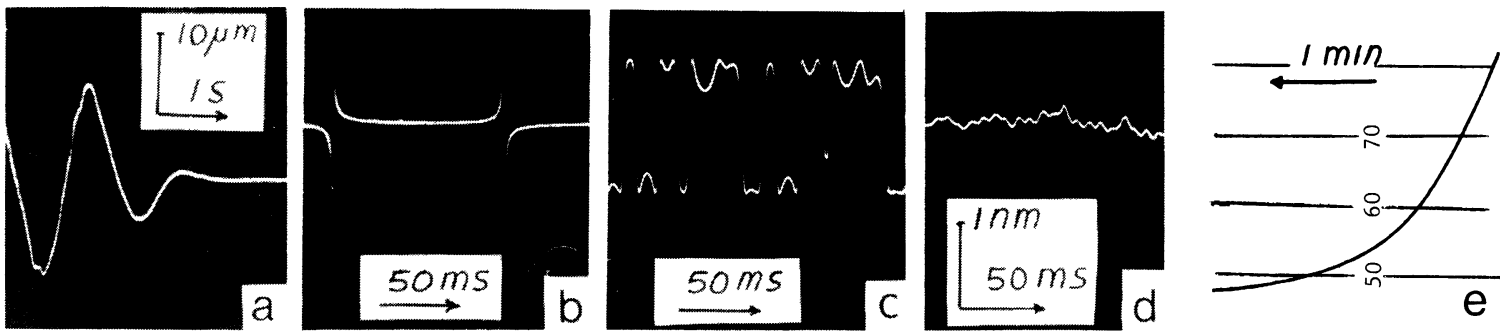

Fig. 2. - Typical system waveforms as described in text. 
orders of magnitude improvement are expected when the accelerometer is operated in a vibration-isolated system with a $0.1 \mathrm{~m} \times 1 \mathrm{~m}$ antenna. Further developments nearing completion include a SQUID coupled to the energising transformer to improve the damping, frequency stabilization with a $\mathrm{Nb}$ cavity to reduce phase noise in the microwave signal, and low noise parametric amplification of the re-entrant cavity signal.

We thank M. McAshan of Stanford University for annealing the niobium and the Australian Research Grants Commission for their support.

\section{References}

[1] Rand, R. E. and Blair, D. G., Aust. Phys. 14 (1977) 131.

[2] Blair, D. G., Mills, J., Rand, R. E., IEEE Trans. Mag. MAG 13 (1976) 350.

[3] Smythe, W. R., Stat. \& Dyn. Elect., 3rd ed. (McGraw Hill, N. Y.) 1978 , p. 371.
[4] Ferreirinho, J., Blair, D. G., Applications of Flux Trapping, to be published.

[5] Mann, A. G. and Blair, D. G., Levitation Monitor, to be published. 